\title{
Effect of rosuvastatin on high glucose-induced endoplasmic reticulum stress in human umbilical vein endothelial cells
}

\author{
J.Z. Xu ${ }^{1}$, Y.L. Chai ${ }^{1,2}$ and Y.L. Zhang ${ }^{1}$ \\ ${ }^{1}$ Department of Cardiovascular Medicine, \\ First Affiliated Hospital of China Medical University, Shenyang, Liaoning, China \\ ${ }^{2}$ No. 1 Department of Cardiovascular Medicine, \\ People's Hospital of Jiangxi Province, Nanchang, Jiangxi, China \\ Corresponding author: Y.L. Zhang \\ E-mail: Zhangzyl3@sina.com
}

Genet. Mol. Res. 15 (4): gmr15048935

Received July 1, 2016

Accepted August 15, 2016

Published October 17, 2016

DOI http://dx.doi.org/10.4238/gmr15048935

Copyright (C) 2016 The Authors. This is an open-access article distributed under the terms of the Creative Commons Attribution ShareAlike (CC BY-SA) 4.0 License.

\begin{abstract}
It is well established that endothelial injury plays an essential role in atherosclerotic plaque formation. Accumulating evidence has shown that high glucose levels may detrimentally affect cultured endothelial cells through endoplasmic reticulum (ER) stress. In this study, we investigated the effect of rosuvastatin on high glucoseinduced ER stress in human umbilical vein endothelial cells (HUVECs). HUVECs treated with $30 \mathrm{mM}$ glucose were used to simulate high-glucose conditions, and rosuvastatin concentrations ranging from 0.1 to $10 \mathrm{nM}$ were used. Cell viability was analyzed by thiazolyl blue tetrazolium bromide assay, and apoptosis rate was measured using flow cytometry. Expression of GRP78, IRE1 $\alpha, \mathrm{XBP} 1 \mathrm{~s}$, and CHOP was quantified using western blot and real-time polymerase chain reaction. Compared to cells treated with high glucose alone, cell viability increased and apoptosis
\end{abstract}


rate decreased significantly in the rosuvastatin + high-glucose groups. Furthermore, GRP78, IRE1 $\alpha$, XBP1s, and CHOP expression was downregulated as a result of rosuvastatin administration. These results suggest that rosuvastatin may protect HUVECs from injury induced by high glucose levels, through alleviation of ER stress.

Key words: Rosuvastatin; Endoplasmic reticulum stress; High glucose

\section{INTRODUCTION}

Cardiovascular disease is a serious complication of diabetes and is associated with a high-mortality rate. Cardiovascular disease risk for diabetes patients is two to four times higher than among healthy individuals (Haffner, 2006), and many studies have demonstrated that hyperglycemia is an independent risk factor for the early phase of atherosclerosis (Funk et al., 2012). It has also been established that endothelial cell dysfunction is involved in atherosclerotic plaque formation (Onat et al., 2011). In the past few decades, the effect of hyperglycemia on vascular endothelial cells has been widely studied. Research involving both animal models and patients has demonstrated a correlation between hyperglycemia and endothelial cell dysfunction (Mah and Bruno, 2012). Endothelial cells cultured in high glucose (HG) medium exhibit reduced nitric oxide production (Kemeny et al., 2013) and enhanced expression of inflammation-related genes (Safi et al., 2015). The mechanisms responsible may include accumulation of advanced glycation end products (Janket et al., 2008), increased reactive oxygen species (ROS) production (Cifarelli et al., 2011), activation of protein kinase C (PKC) signaling (Batchuluun et al., 2014), and endoplasmic reticulum (ER) stress (Schisano et al., 2012). We believe that this latter plays a crucial role in endothelial dysfunction, as it is capable of causing a series of pathological changes influencing the inflammatory response and apoptosis (Kim et al., 2007).

As is well known, the ER is a multifunctional organelle that organizes the synthesis of proteins and lipids and regulates calcium homeostasis, all of which are characterized by a high $\mathrm{Ca}^{2+}$ concentration and specific redox environment (Michalak and Gye, 2015). When homeostasis of the ER is disrupted by hypoxia or cell toxicity, its function is impaired, leading to the buildup of misfolded or unfolded proteins within this organelle (Cominacini et al., 2015). To restore ER homeostasis, a complex intracellular program known as the unfolded protein response (UPR) is activated as a coping strategy (Sozen et al., 2015). This involves inhibiting synthesis of new proteins by blocking translation, activating the transcription of genes encoding protein folding chaperones, and mediating ER-associated protein degradation to reduce the number of misfolded proteins (Qiu et al., 2014). If these steps are insufficient to reestablish ER homeostasis, apoptotic pathways are activated to eliminate the defective cell (Tabas and Ron, 2011).

Rosuvastatin(Ros) lowers blood cholesterol by inhibiting 3-hydroxy-3-methylglutarylcoenzyme A (HMG-CoA) reductase, the rate-limiting enzyme in cholesterol biosynthesis. It also increases the number of low-density lipoprotein (LDL) receptors on hepatocytes to enhance the uptake and catabolism of LDL by the liver (Huang et al., 2012). Much research over recent years has gradually brought the powerful cardiovascular protective action and other pharmacological effects of statins into public view. For example, atorvastatin protects against atherosclerosis by increasing the expression of nitric oxide synthase in endothelial

Genetics and Molecular Research 15 (4): gmr15048935 
cells (Kesavan et al., 2014) and promoting their regeneration after hypoxic injury (Chaudagar and Mehta, 2014). In addition, lovastatin has been shown to reduce the expression of CD40/ CD40L induced by hs-CRP in human umbilical vein endothelial cells (HUVECs; Lin et al., 2004), and the anti-atherosclerotic effect of Ros has been associated with its anti-inflammatory influence (Srivastava et al., 2009). However, the effects of Ros on ER stress have thus far not been elucidated. In the present study, we investigated whether Ros protects endothelial cells through inhibition of ER stress.

\section{MATERIAL AND METHODS}

\section{Cells and reagents}

HUVECs were purchased from Shanghai Bogoo Biotechnology (Shangai, China). Fetal bovine serum (FBS), Dulbecco's modified Eagle's medium (DMEM)/F12, and trypsin (containing ethylenediaminetetraacetic acid) were purchased from HyClone (Logan, UT, USA). Endothelial cell growth supplement (ECGS) was purchased from ScienCell Research Laboratories (San Diego, CA, USA). Ros was purchased from Dalian Meilun Biology Technology (Dalian, China). Thiazolyl blue tetrazolium bromide (MTT) and dimethyl sulfoxide (DMSO) were purchased from Sigma-Aldrich (St. Louis, MO, USA). An annex in V-fluorescein is othiocyanate (FITC) apoptosis detection kit was purchased from KeyGen Biotech (Nanjing, China). Radio immunoprecipitation assay (RIPA) lysis buffer, a bicinchoninic acid (BCA) protein assay kit, antibody dilution solution, and $5 \mathrm{X}$ sodium dodecyl sulfate-polyacrylamide gel electrophoresis (SDS-PAGE) sample loading buffer were purchased from Beyotime Biotechnology (Shanghai, China). TRIzol reagent was purchased from Invitrogen (Carlsbad, CA, USA). A Prime Script RT Reagent Kit and SYBR Premix Ex Taq II (TIi RNaseH Plus) were purchased from TaKaRa Bio (Tokyo, Japan). Primers targeting glucose-regulated protein 78 (GRP78), inositol-requiring enzyme $1 \alpha$ (IRE1 $\alpha), X B P 1 s, C H O P$, and GAPDH were synthesized by Sangon Biotech (Shanghai, China). Rabbit anti-GRP78, anti-IRE1 $\alpha$, and anti$\mathrm{XBP} 1 \mathrm{~s}$, and mouse anti-CHOP monoclonal antibodies were purchased from Cell Signaling Technology (Beverly, MA, USA). Horseradish peroxidase (HRP)-conjugated goat anti-mouse and goat anti-rabbit antibodies were supplied by ZSGB-BIO (Beijing, China). Polyvinylidene difluoride (PVDF) membrane $(0.45 \mathrm{~mm})$ was purchased from Millipore (Billerica, MA, USA).

\section{Cell culture and treatments}

HUVECs were incubated in modified DMEM/F12 (10\% FBS, 1\% ECGS, and $100 \mathrm{U} /$ $\mathrm{mL}$ penicillin/streptomycin) containing $5 \mathrm{mM}$ D-glucose at $37^{\circ} \mathrm{C}$ in a humidified atmosphere of $5 \% \mathrm{CO}_{2}$ in air until $80 \%$ confluent. They were then exposed to high $(30 \mathrm{mM})$ glucose medium and $10,1,0.1$, or $0 \mathrm{nM}$ Ros for $24 \mathrm{~h}$, being randomly assigned to one of these treatment groups. Cells of the control group were kept in normal $(5 \mathrm{mM})$ glucose medium lacking Ros. Medium was replaced every 2-3 days, and $24 \mathrm{~h}$ before the end of the experiment.

\section{Cell viability assay}

Cell viability was measured by MTT assay following the manufacturer protocol. Briefly, HUVECs were placed on 96-well plates at 5000 cells/well. After treatment as above,

Genetics and Molecular Research 15 (4): gmr15048935 
cells were incubated with $0.5 \mathrm{mg} / \mathrm{mL}$ MTT for $4 \mathrm{~h}$, then lysed with DMSO. Optical absorbance was subsequently measured at $492 \mathrm{~nm}$ using a microplate reader. Cell viability (\%) was determined by the formula: $(\mathrm{T}-\mathrm{B}) /(\mathrm{C}-\mathrm{B}) \times 100 \%$, where $\mathrm{T}$ represents the value of the treatment group, $\mathrm{C}$ that of the control group, and $\mathrm{B}$ that of the blank control group. Each experiment was performed independently three times.

\section{Analysis of apoptosis by flow cytometry}

Cells were collected after treatment and washed twice with cold phosphate-buffered saline (PBS). They were then resuspended at $1 \times 10^{6} / \mathrm{mL}$ in $500 \mu \mathrm{L}$ binding buffer [included in the annexin V-FITC/propidium iodide (PI) apoptosis detection kit], and treated with $5 \mu \mathrm{L}$ annexin V-FITC and $5 \mu \mathrm{L}$ PI following the manufacturer protocol. Subsequently, the cells were incubated for 5-15 min before apoptosis rate was measured by flow cytometry.

\section{Real-time polymerase chain reaction (RT-PCR)}

Total RNA was extracted with TRIzol reagent following the manufacturer protocol, and a PrimeScript RT Reagent Kit was used to synthesize complementary DNA. The following primers were used: GRP78, 5'-TAGCGTATGGTGCTGCTGTC-3' and 5'-CCTTGGAATCAGTTTGGTCAT-3'; IRE 1 $\alpha, 5$ '-GGGCGAACAGAATACACCAT-3' and 5'-TGGACACAAAGTGGGACATC-3'; XBP1s, 5'-TATCCTGTTGGGCATTCTGG-3' and 5'-ACTGGGTCCTTCTGGGTAGAC-3'; CHOP, 5'-TGGAAGCCTGGTATGAGGAC-3' and 5'-TGTGACCTCTGCTGGTTCTG-3'; and GAPDH (used as a reference gene), 5'-CAGGAGGCATTGCTGATGAT-3' and 5'-GAAGGCTGGGGCTCATTT-3'. RT-PCR was performed using SYBR Premix Ex Taq II (TIi RNaseH Plus) and the following cycling conditions: $95^{\circ} \mathrm{C}$ for $5 \mathrm{~min}$, followed by eight cycles of $95^{\circ} \mathrm{C}$ for $30 \mathrm{~s}, 60^{\circ} \mathrm{C}$ for $45 \mathrm{~s}$, and $72^{\circ} \mathrm{C}$ for $20 \mathrm{~s}$; then 35 cycles of $95^{\circ} \mathrm{C}$ for $30 \mathrm{~s}, 56^{\circ} \mathrm{C}$ for $45 \mathrm{~s}$, and $72^{\circ} \mathrm{C}$ for $20 \mathrm{~s}$, with a final extension at $95^{\circ} \mathrm{C}$ for $1 \mathrm{~min}, 55^{\circ} \mathrm{C}$ for $30 \mathrm{~s}$, and $95^{\circ} \mathrm{C}$ for $30 \mathrm{~s}$.

\section{Western blot}

HUVECs were washed three times with cold PBS after treatment. Cells were collected and lysed for $30 \mathrm{~min}$ on ice in RIPA buffer containing a protease inhibitor cocktail, before being centrifuged at $12,000 \mathrm{rpm}$ for $15 \mathrm{~min}$ at $4{ }^{\circ} \mathrm{C}$ to obtain the protein-containing supernatant. Protein concentration was then measured with a BCA assay kit. The proteins were separated by $10-12 \%$ SDS-PAGE and transferred to a $0.45-\mu \mathrm{m}$ PVDF membrane, which was then blocked in 5\% skim milk for $1 \mathrm{~h}$ at room temperature, and incubated with primary antibodies at $4{ }^{\circ} \mathrm{C}$ overnight. The membranes were then washed three times with Tris-buffered saline-Tween 20 and incubated with HRP-conjugated secondary antibodies for $1 \mathrm{~h}$ at room temperature. The expression of various proteins was subsequently visualized by enhanced chemiluminescence.

\section{Statistical analysis}

Data were analyzed by SPSS (SPSS Inc., Chicago, IL, USA) and are reported as means \pm standard deviations. Groups were compared using one-way analysis of variance 
and the Student-Newman-Keuls test for multiple comparisons. Differences were considered significant at $\mathrm{P}<0.05$.

\section{RESULTS}

\section{HG levels decreased HUVEC viability}

HUVECs were incubated for various lengths of time $(6,12$, or $24 \mathrm{~h})$ with different concentrations of glucose $(5,10,15,20,25$, or $30 \mathrm{mM})$. Cell viability in each treatment group was measured by MTT assay. We found that the longer the incubation time, the more obvious the negative effect of HG concentration on cell viability became (Figure 1A). Cells treated for $24 \mathrm{~h}$ with 30 and $5 \mathrm{mM}$ glucose were defined as the high (HG) and normal (NG) glucose groups, respectively.
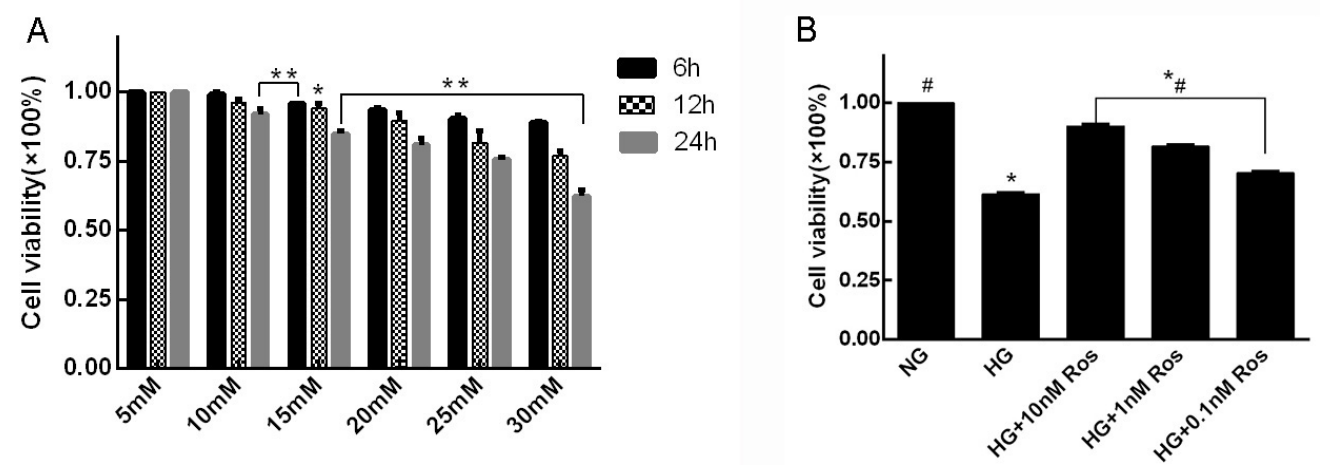

Figure 1. A. Effect of glucose on cell viability. Human umbilical vein endothelial cells (HUVECs) were exposed to $5,10,15,20,25$, or $30 \mathrm{mM}$ glucose for 6,12 , or $24 \mathrm{~h}$, and cell viability was tested by thiazolyl blue tetrazolium bromide (MTT) assay. B. Effect of rosuvastatin (Ros) on cell viability. HUVECs were exposed to $30 \mathrm{mM}$ glucose (HG) and $0,10,1$, or $0.1 \mathrm{nM}$ Ros for $24 \mathrm{~h}$, while the control group was treated with $5 \mathrm{mM}$ glucose (NG). Cell viability was tested by MTT assay. $\mathrm{N}=3$ per group. ${ }^{*} \mathrm{P}<0.05 v s$ the $\mathrm{NG}$ group; ${ }^{*} * \mathrm{P}<0.05 v s$ the previous concentration; ${ }^{*} \mathrm{P}<0.05$ vs the $\mathrm{HG}$ group.

\section{Effect of Ros on cell viability}

Cells were divided into NG, HG, HG + $10 \mathrm{nM}$ Ros, $\mathrm{HG}+1 \mathrm{nM}$ Ros, and $\mathrm{HG}+0.1 \mathrm{nM}$ Ros groups. Cell viability was measured by MTT assay after exposure to the corresponding glucose and Ros concentrations for $24 \mathrm{~h}$. As shown in Figure 1B, cell viability in the HG group was sharply diminished compared to that in the NG group. However, this reduction was reversed in a dose-dependent manner by administration of Ros.

\section{Effect of Ros on cell apoptosis}

Cell apoptosis rate was measured with an annex in V-FITC/PI assay employing flow cytometry. The apoptosis rate of cells in the HG group was significantly higher than that of those in the NG group. However, HG-induced apoptosis was significantly decreased in a dosedependent fashion when cells were treated with Ros (Figure 2). 

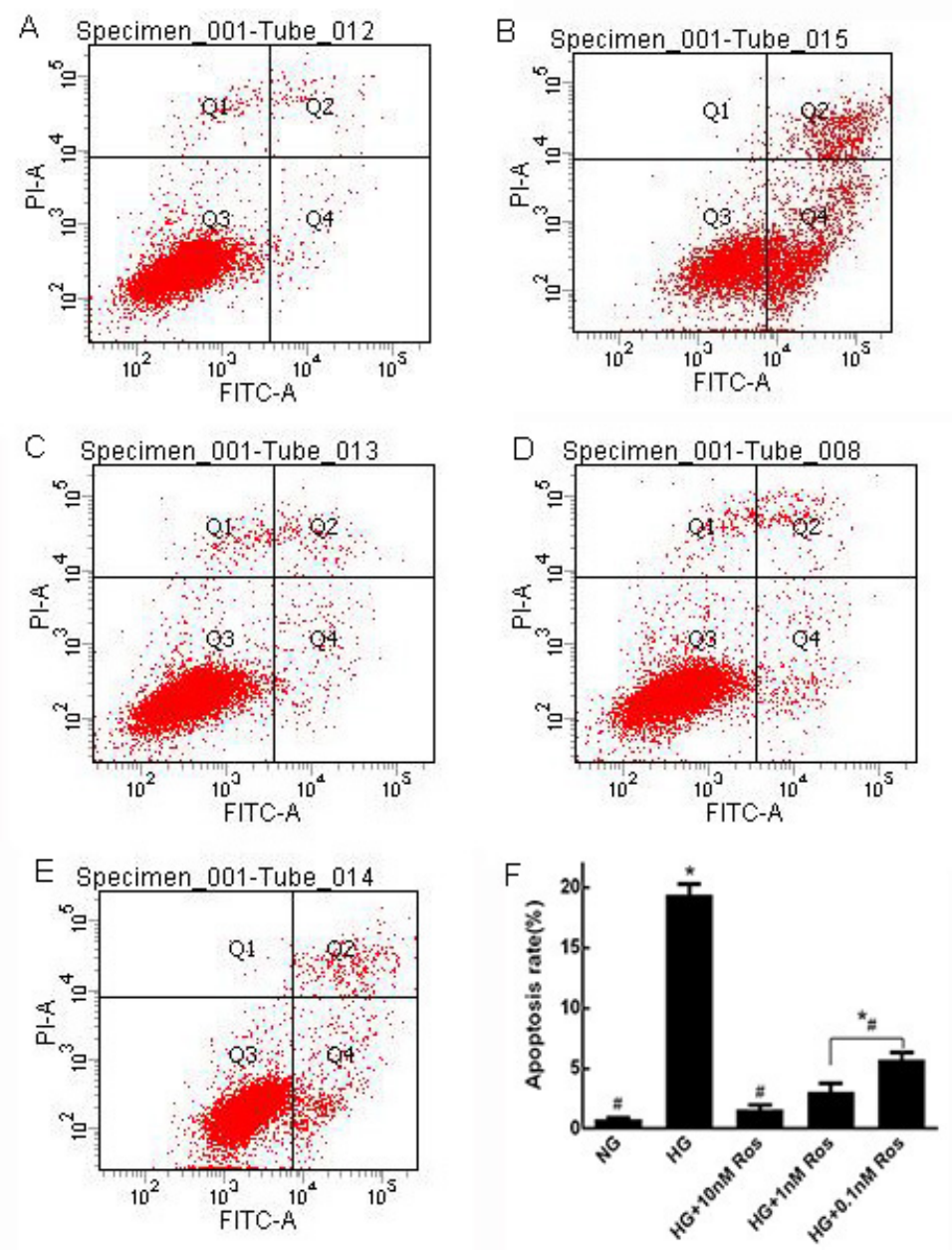

Figure 2. Effect of rosuvastatin (Ros) on cell apoptosis induced by high glucose levels (HG). Human umbilical vein endothelial cells were exposed to $\mathrm{HG}(30 \mathrm{mM})$ or $\mathrm{HG}+10$, 1, or $0.1 \mathrm{nM}$ Ros for $24 \mathrm{~h}$. Cell apoptosis rate was then measured by flow cytometry. The control group was incubated under normal glucose conditions (NG; $5 \mathrm{mM})$ for 24 h. $\mathrm{N}=3$ per group. A. NG; B. HG; C. HG $+10 \mathrm{nM}$ Ros; D. HG + $1 \mathrm{nM}$ Ros; E. HG + $0.1 \mathrm{nM}$ Ros. F. Apoptosis rate in each group. ${ }^{*} \mathrm{P}<0.05$ vs the $\mathrm{NG}$ group; ${ }^{*} \mathrm{P}<0.05$ vs the $\mathrm{HG}$ group. $\mathrm{FITC}=$ fluorescein isothiocyanate, $\mathrm{PI}=$ propidium iodide.

\section{Effect of Ros on ER stress}

GRP78, a chaperone released from the ER membrane, is abundantly expressed during ER stress (Chistiakov et al., 2015). Here, its expression was measured by RT-PCR and western blot. As shown in Figure 3A, C, and D, levels of GRP78 mRNA and protein were significantly higher in the HG group than in the NG group. However, the HG-induced upregulation of GRP78 was markedly lower in cells of the $\mathrm{HG}+10 \mathrm{nM}$ Ros group. This effect was weaker in the HG $+1 \mathrm{nM}$ Ros group, and no significant decrease in GRP78 mRNA or protein was evident in the $\mathrm{HG}+0.1 \mathrm{nM}$ Ros group compared with the HG group. We also measured expression of 
IRE1 $\alpha$, an ER transmembrane protein that mediates one of the UPR pathways, and that of its downstream factor XBP1s (Bruno et al., 2014) to confirm the presence of ER stress. As shown in Figure 3A, E, and F, both IRE1 $\alpha$ mRNA and protein levels were sharply elevated in the HG group compared with the NG group. This increase was suppressed by Ros in a dose-dependent manner. However, no significant difference in IRE1 $\alpha$ expression was observed between the $\mathrm{HG}+0.1 \mathrm{nM}$ Ros and HG groups. Expression of XBP1s was consistent with that of IRE1 $\alpha$ when comparing the HG and NG groups, and Ros reduced these raised XBP1s mRNA and protein levels in a dose-dependent fashion (Figure 3B, G, and H). The expression of CHOP, a key indicator of apoptosis signaling induced by ER stress (Tabas and Ron, 2011), was also assessed. As shown in Figure 3B, I, and J, CHOP mRNA and protein levels were increased in cells of the HG group compared with those of the NG group. However, this increase was suppressed by rosuvastatin in the $\mathrm{HG}+10$ and $1 \mathrm{nM}$ Ros groups. No significant difference was established between the $\mathrm{HG}+0.1 \mathrm{nM}$ Ros and $\mathrm{HG}$ groups.

A

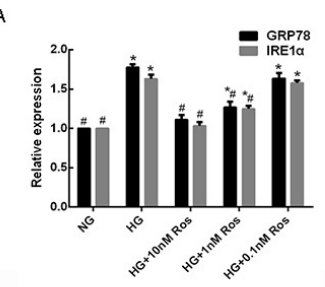

C

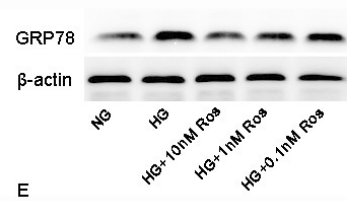

$E$

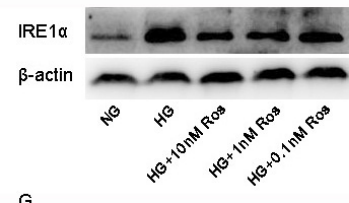

G

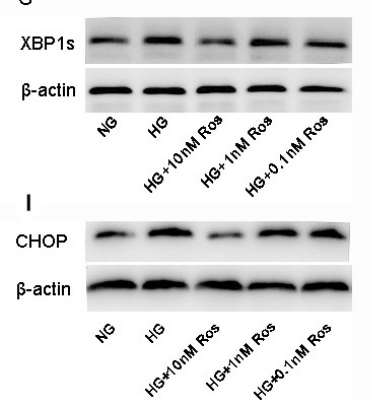

B
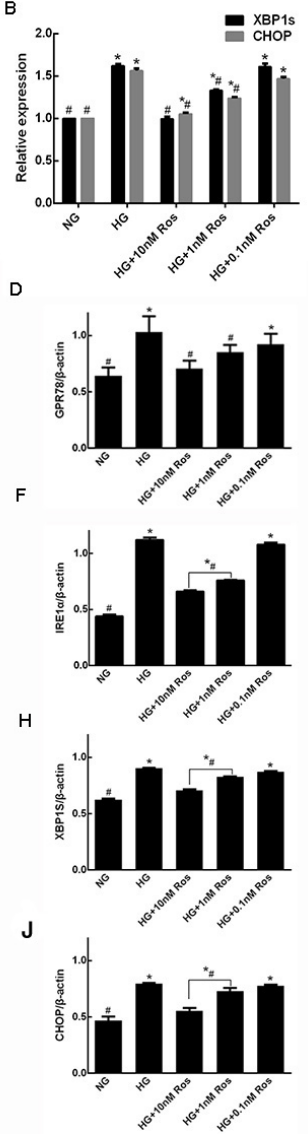

Figure 3. Effect of rosuvastatin (Ros) on endoplasmic reticulum stress. Human umbilical vein endothelial cells were exposed to high glucose conditions (HG; $30 \mathrm{mM})$, or $\mathrm{HG}+10$, 1, or $0.1 \mathrm{nM}$ Ros for $24 \mathrm{~h}$. mRNA and protein levels of GRP78 (A, C, and D), IRE1 $\alpha(\mathbf{A}, \mathbf{E}$, and F), XBP1s (B, G, and $\mathbf{H})$, and CHOP $(\mathbf{B}, \mathbf{I}$, and $\mathbf{J})$ were then measured by real-time polymerase chain reaction and western blot. The control group was incubated under normal glucose conditions $\left(\mathrm{NG} ; 5 \mathrm{mM}\right.$ ) for $24 \mathrm{~h}$. ${ }^{*} \mathrm{P}<0.05$ vs the $\mathrm{NG}$ group; ${ }^{*} \mathrm{P}<0.05$ vs the HG group. 


\section{DISCUSSION}

This study showed that ER stress participated in HUVEC injury induced by HG levels, against which, Ros demonstrated a preventive effect. Several findings support this conclusion. First, cell viability was not affected by the lower glucose concentrations and shorter incubation times, but did diminish when these variables were increased, with cells exposed to $30 \mathrm{mM}$ glucose for $24 \mathrm{~h}$ showing the lowest viability. This result indicates that glucose exerts a dose- and time-dependent effect on HUVEC viability. Second, compared to the NG group, HG significantly upregulated both mRNA and protein expression of GRP78, IRE1 $\alpha$, and XBP1s, implying that ER stress is involved in HG-induced cell injury. Third, Ros downregulated expression of ER stress-related factors and reduced cell apoptosis rate, while increasing HUVEC viability. In summary, we speculate that ER stress plays a role in HUVEC injury induced by HG concentration, and Ros protects against this by inhibiting such stress.

A considerable number of studies have demonstrated that HG levels lead to endothelial cell dysfunction (Haffner, 2006; Funk et al., 2012), which is thought to be the first step in atherosclerotic plaque formation (Ruggiero et al., 2013; Bruno et al., 2014; Chistiakov et al., 2015), a process involving a series of molecular mechanisms, including activation of oxidative stress, PKC signaling, and ER stress (Mah and Bruno, 2012; Kemeny et al., 2013; Safi et al., 2015). In terms of biological characteristics, HUVECs are similar to artery endothelial cells, and have been widely used as a model to study endothelial cell function (Park et al., 2006). In the present study, we showed that HG concentrations decreased viability of endothelial cells and increased their apoptosis, while lower concentrations had no effect. These findings are consistent with those of previous investigations (Schisano et al., 2012). Importantly, we also established that ER stress can be induced by HG levels.

ER stress occurs when cells are in specific pathophysiological states and the ER protein folding function is disturbed. The UPR, known to be a crucial defensive mechanism in ER stress, is mediated by three transmembrane proteins: IRE1, protein kinase R-like endoplasmic reticulum kinase, and activating transcription factor 6 . Under normal conditions, these proteins are maintained in an inactivate state by being bound to GRP78, a chaperone considered an indicator of ER stress. Once the homeostasis of the ER is disturbed and its functionality impaired, GRP78, as a sensor of misfolded proteins, dissociates from these transmembrane proteins, leading to activation of the three corresponding pathways. Certain degrees of stress can be overcome, with cells resuming homeostasis by inhibiting protein synthesis and enhancing the protein folding ability of the ER. However, excessive or prolonged stress may lead to cell apoptosis (Tabas and Ron, 2011; Qiu et al., 2014; Sozen et al., 2015). In this study, we found that GRP78 mRNA and protein expression levels were significantly increased in the HG group compared with the NG group, indicating that HG induced ER stress. IRE1 $\alpha$, one of the abovementioned transmembrane proteins, and its downstream factor XBP1s were also examined to verify the occurrence of ER stress. These proteins were more highly expressed in the HG group than the NG group at both transcriptional and translational levels; therefore, we concluded that a high concentration of glucose induced ER stress. We then measured expression of CHOP, a pro-apoptosis factor induced by ER stress (Tabas and Ron, 2011; Chai et al., 2016), to ascertain the degree of ER stress resulting from HG conditions. CHOP mRNA and protein levels in the HG group were significantly higher than those in the NG group. This result was consistent with changes in apoptosis rate, indicating that $\mathrm{HG}$ concentrations and long exposure periods caused irreversible ER dysfunction, leading to cell apoptosis.

Genetics and Molecular Research 15 (4): gmr15048935 
The most important finding of the present study was that Ros can protect HUVECs from HG-associated injury by inhibiting ER stress. First, cells exposed to HG conditions and Ros showed significantly increased viability and reduced apoptosis rates compared to those in the HG group. Second, elevated expression of GRP78, IRE1 $\alpha$, XBP1s, and CHOP in HG cells was decreased by Ros treatment at both mRNA and protein levels in a dose-dependent manner. These findings revealed that Ros mitigated ER stress caused by a HG environment. However, we observed that the smallest Ros concentration $(0.1 \mathrm{nM})$ had no significant effect on either mRNA or protein expression of ER stress-related factors. We speculate that Ros acts as a transcriptional inhibitor during ER stress, and that this effect is dependent on concentration.

Ros has been shown to have multiple effects besides inhibition of HMG-CoA reductase, such as increasing nitric oxide synthase expression (Huang et al., 2012; Omanwar and Fahim, 2015), decreasing ROS-mediated stress (Mahalwar and Khanna, 2013), and exerting anti-inflammatory actions (Srivastava et al., 2009). However, its effect on ER stress has not previously been reported. In this study, we showed that Ros protected endothelial cells from HG-related injury by inhibiting ER stress. Although the mechanism responsible needs to be explored further, this study provides a theoretical basis for the protection of endothelial cells from HG conditions, and identifies possible drug targets.

\section{Conflicts of interest}

The authors declare no conflict of interest.

\section{ACKNOWLEDGMENTS}

We would like to thank all of the members of the pharmacology laboratory at the China Medical University who provided us with laboratory and technical support. Research supported by educational science foundation of Liaoning Province.

\section{REFERENCES}

Batchuluun B, Inoguchi T, Sonoda N, Sasaki S, et al. (2014). Metformin and liraglutide ameliorate high glucose-induced oxidative stress via inhibition of PKC-NAD(P)H oxidase pathway in human aortic endothelial cells. Atherosclerosis 232: 156-164. http://dx.doi.org/10.1016/j.atherosclerosis.2013.10.025

Bruno RM, Gori T and Ghiadoni L (2014). Endothelial function testing and cardiovascular disease: focus on peripheral arterial tonometry. Vasc. Health Risk Manag. 10: 577-584.

Chai YL, Xu JZ, Zhang YL and Sheng GT (2016). Effects of probucol on cultured human umbilical vein endothelial cells injured by hypoxia/reoxygenation. Genet. Mol. Res. 15: 15016752.

Chaudagar KK and Mehta AA (2014). Effect of atorvastatin on the angiogenic responsiveness of coronary endothelial cells in normal and streptozotocin (STZ) induced diabetic rats. Can. J. Physiol. Pharmacol. 92: 338-349. http://dx.doi. org/10.1139/cipp-2013-0391

Chistiakov DA, Revin VV, Sobenin IA, Orekhov AN, et al. (2015). Vascular endothelium: functioning in norm, changes in atherosclerosis and current dietary approaches to improve endothelial function. Mini Rev. Med. Chem. 15: 338-350. http://dx.doi.org/10.2174/1389557515666150226114031

Cifarelli V, Geng X, Styche A, Lakomy R, et al. (2011). C-peptide reduces high-glucose-induced apoptosis of endothelial cells and decreases $\mathrm{NAD}(\mathrm{P}) \mathrm{H}$-oxidase reactive oxygen species generation in human aortic endothelial cells. Diabetologia 54: 2702-2712. http://dx.doi.org/10.1007/s00125-011-2251-0

Cominacini L, Mozzini C, Garbin U, Pasini A, et al. (2015). Endoplasmic reticulum stress and Nrf2 signaling in cardiovascular diseases. Free Radic. Biol. Med. 88 (Pt B): 233-242. http://dx.doi.org/10.1016/j.freeradbiomed.2015.05.027

Funk SD, Yurdagul Jr A and Orr AW (2012). Hyperglycemia and endothelial dysfunction in atherosclerosis: lessons from

Genetics and Molecular Research 15 (4): gmr15048935 
type 1 diabetes. Int. J. Vasc. Med. 2012: 569654. http://dx.doi.org/10.1155/2012/569654

Haffner SM (2006). The metabolic syndrome: inflammation, diabetes mellitus, and cardiovascular disease. Am. J. Cardiol. 97 (2A): 3A-11A. http://dx.doi.org/10.1016/j.amjcard.2005.11.010

Huang B, Li FA, Wu CH and Wang DL (2012). The role of nitric oxide on rosuvastatin-mediated $S$-nitrosylation and translational proteomes in human umbilical vein endothelial cells. Proteome Sci. 10: 43. http://dx.doi. org/10.1186/1477-5956-10-43

Janket SJ, Jones JA, Meurman JH, Baird AE, et al. (2008). Oral infection, hyperglycemia, and endothelial dysfunction. Oral Surg. Oral Med. Oral Pathol. Oral Radiol. Endod. 105: 173-179. http://dx.doi.org/10.1016/j.tripleo.2007.06.027

Kemeny SF, Figueroa DS and Clyne AM (2013). Hypo- and hyperglycemia impair endothelial cell actin alignment and nitric oxide synthase activation in response to shear stress. PLoS One 8: e66176. http://dx.doi.org/10.1371/journal. pone. 0066176

Kesavan M, Sarath TS, Kannan K, Suresh S, et al. (2014). Atorvastatin restores arsenic-induced vascular dysfunction in rats: modulation of nitric oxide signaling and inflammatory mediators. Toxicol. Appl. Pharmacol. 280: 107-116. http://dx.doi.org/10.1016/j.taap.2014.07.008

Kim KM, Pae HO, Zheng M, Park R, et al. (2007). Carbon monoxide induces heme oxygenase-1 via activation of protein kinase R-like endoplasmic reticulum kinase and inhibits endothelial cell apoptosis triggered by endoplasmic reticulum stress. Circ. Res. 101: 919-927. http://dx.doi.org/10.1161/CIRCRESAHA.107.154781

Lin R, Liu J, Gan W and Yang G (2004). C-reactive protein-induced expression of CD40-CD40L and the effect of lovastatin and fenofibrate on it in human vascular endothelial cells. Biol. Pharm. Bull. 27: 1537-1543. http://dx.doi. org/10.1248/bpb.27.1537

Mah E and Bruno RS (2012). Postprandial hyperglycemia on vascular endothelial function: mechanisms and consequences. Nutr. Res. 32: 727-740. http://dx.doi.org/10.1016/j.nutres.2012.08.002

Mahalwar R and Khanna D (2013). Pleiotropic antioxidant potential of rosuvastatin in preventing cardiovascular disorders. Eur. J. Pharmacol. 711: 57-62. http://dx.doi.org/10.1016/j.ejphar.2013.04.025

Michalak M and Gye MC (2015). Endoplasmic reticulum stress in periimplantation embryos. Clin. Exp. Reprod. Med. 42: 1-7. http://dx.doi.org/10.5653/cerm.2015.42.1.1

Omanwar S and Fahim M (2015). Mercury exposure and endothelial dysfunction: an interplay between nitric oxide and oxidative stress. Int. J. Toxicol. 34: 300-307. http://dx.doi.org/10.1177/1091581815589766

Onat D, Brillon D, Colombo PC and Schmidt AM (2011). Human vascular endothelial cells: a model system for studying vascular inflammation in diabetes and atherosclerosis. Curr. Diab. Rep. 11: 193-202. http://dx.doi.org/10.1007/ $\underline{\text { s11892-011-0182-2 }}$

Park HJ, Zhang Y, Georgescu SP, Johnson KL, et al. (2006). Human umbilical vein endothelial cells and human dermal microvascular endothelial cells offer new insights into the relationship between lipid metabolism and angiogenesis. Stem Cell Rev. 2: 93-102. http://dx.doi.org/10.1007/s12015-006-0015-x

Qiu ZL, Zhang JP and Guo XC (2014). Endoplasmic reticulum stress and vascular endothelial cell apoptosis. Zhongguo Yi Xue Ke Xue Yuan Xue Bao 36: 102-107.

Ruggiero D, Paolillo S, Ratta GD, Mariniello A, et al. (2013). Endothelial function as a marker of pre-clinical atherosclerosis: assessment techniques and clinical implications. Monaldi Arch. Chest Dis. 80: 106-110.

Safi SZ, Batumalaie K, Mansor M, Chinna K, et al. (2015). Glutamine treatment attenuates hyperglycemia-induced mitochondrial stress and apoptosis in umbilical vein endothelial cells. Clinics 70: 569-576. http://dx.doi.org/10.6061/ clinics/2015(08)07

Schisano B, Harte AL, Lois K, Saravanan P, et al. (2012). GLP-1 analogue, Liraglutide protects human umbilical vein endothelial cells against high glucose induced endoplasmic reticulum stress. Regul. Pept. 174: 46-52. http://dx.doi. org/10.1016/j.regpep.2011.11.008

Sozen E, Karademir B and Ozer NK (2015). Basic mechanisms in endoplasmic reticulum stress and relation to cardiovascular diseases. Free Radic. Biol. Med. 78: 30-41. http://dx.doi.org/10.1016/j.freeradbiomed.2014.09.031

Srivastava AK, Kalita J, Dohare P, Ray M, et al. (2009). Studies of free radical generation by neurons in a rat model of cerebral venous sinus thrombosis. Neurosci. Lett. 450: 127-131. http://dx.doi.org/10.1016/j.neulet.2008.11.036

Tabas I and Ron D (2011). Integrating the mechanisms of apoptosis induced by endoplasmic reticulum stress. Nat. Cell Biol. 13: 184-190. http://dx.doi.org/10.1038/ncb0311-184

Genetics and Molecular Research 15 (4): gmr15048935 